\title{
Native Electrospray Mass Spectrometry of DNA G-Quadruplexes in Potassium Solution
}

\author{
Adrien Marchand, ${ }^{1,2}$ Valerie Gabelica ${ }^{1,2}$ \\ ${ }^{1}$ University Bordeaux, IECB, ARNA Laboratory, F-33600, Pessac, France \\ ${ }^{2}$ INSERM, U869, ARNA Laboratory, F-33000, Bordeaux, France
}

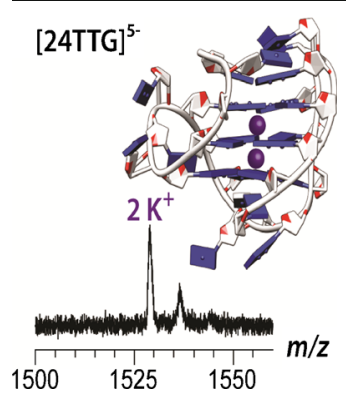

Abstract. A commonly used electrolyte in electrospray mass spectrometry (ESIMS) of biomolecules is ammonium acetate $\left(\mathrm{NH}_{4} \mathrm{OAc}\right)$. Although some nucleic acid structures such as duplexes require only proper physiological ionic strength (whatever the monovalent ions) to be properly folded in ESI-MS conditions, the folding of some other nucleic acid structures such as DNA G-quadruplexes also depends on direct binding of specific cations. Here, we developed ESI-MS compatible conditions that allow one to observe DNA G-quaduplexes with $\mathrm{K}^{+}$ions specifically bound between G-quartets. $\mathrm{NH}_{4} \mathrm{OAc}$ was replaced with trimethylammonium acetate (TMAA), at concentrations up to $150 \mathrm{mM}$ to provide physiological ionic strength, and the solution was doped with $\mathrm{KCl}$ at concentrations up to $1 \mathrm{mM}$. The trimethylammonium ion is too large to coordinate between G-quartets, where only $\mathrm{K}^{+}$ ions bind. Compared with the equivalent $\mathrm{NH}_{4} \mathrm{OAC} / \mathrm{KCl}$ mixtures, the TMAA/KCl mixtures provide cleaner spectra by suppressing the nonspecific adducts, and favor the formation of similar stacking arrangements as in $100 \mathrm{mM} \mathrm{KCl}$ (physiologically relevant cation) for the polymorphic human telomeric DNA G-quadruplexes. This new sample preparation method can be exploited to determine the number of potassium binding sites in new sequences, to screen ligand binding to the structures favored in potassium, and to transfer potassiumbound G-quadruplexes to the mass spectrometer for gas-phase structural probing, as illustrated herein with ion mobility spectrometry experiments.

Key words: DNA structures, G-quadruplexes, Native, Mass spectrometry, Ion mobility, Potassium, Trimethylammonium, Adducts, Cation binding

Received: 28 January 2014/Revised: 11 March 2014/Accepted: 17 March 2014/Published online: 30 April 2014

\section{Introduction}

$\mathrm{G}$ -quadruplexes are non-classical DNA or RNA structures consisting of stacked guanine quartets (G-quartets) made by Hoogsteen hydrogen-bonding between guanines (Figure 1a). Potassium, sodium, or ammonium cations also stabilize the structure by coordinating to the $\mathrm{O} 6$ oxygen of guanines. Owing to their size, ammonium, and potassium ions are located in-between two G-quartets and, therefore, coordinate with eight $\mathrm{O} 6$ atoms, whereas smaller sodium ions can also access the center of G-quartets. Gquadruplexes can be found in vitro in the promoter regions of oncogenes [1-4] or in the human telomeric region [5]. Some recent work from Balasubramanian's group showed

Electronic supplementary material The online version of this article (doi:10.1007/s13361-014-0890-3) contains supplementary material, which is available to authorized users.

Correspondence to: Valerie Gabelica; e-mail: v.gabelica@iecb.u-bordeaux.fr that G-quadruplex DNA structures are present in human cells [6]. Because of their supposed role in cancer, Gquadruplexes are often studied as targets for anti-cancer drugs [7-10].

The most studied G-quadruplex forming sequence is probably the human telomeric sequence, consisting of $(\text { TAGGGT })_{n}$ repeats. Human telomeric G-quadruplexes present a high level of polymorphism in vitro depending on their core sequence, flanking bases, salt conditions, the nature of the sugar (DNA versus RNA),.. [11]. For example, parallel G-quadruplexes have been reported by X-ray crystallography studies for $\mathrm{d}\left(\mathrm{A}(\mathrm{GGGTTA})_{3} \mathrm{GGG}\right)$ in $\mathrm{K}^{+}$conditions (Figure 1b) [12]. In contrast, by NMR in solution, an antiparallel basket-type form with three Gquartets was observed in $\mathrm{Na}^{+}$conditions for $\mathrm{d}\left(\mathrm{A}(\mathrm{GGGTTA})_{3} \mathrm{GGG}\right)$ (Figure 1c) [13], and one with only two G-quartets in $\mathrm{K}^{+}$conditions for $\mathrm{d}\left((\mathrm{GGGTTA}){ }_{3} \mathrm{GGGT}\right)$ [14]. In $\mathrm{K}^{+}$solution, a hybrid form can also be adopted by sequences d(TT(GGGTTA) ${ }_{3}$ GGGA) (Figure 1d) [15], 
(a)

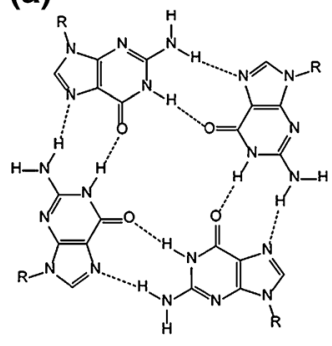

(c)

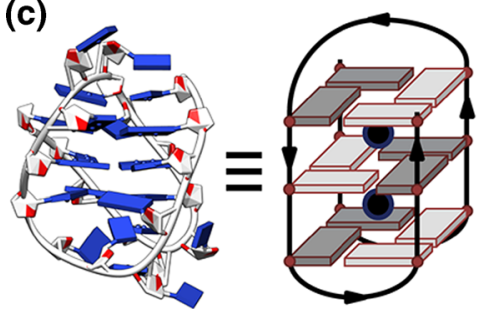

(b)

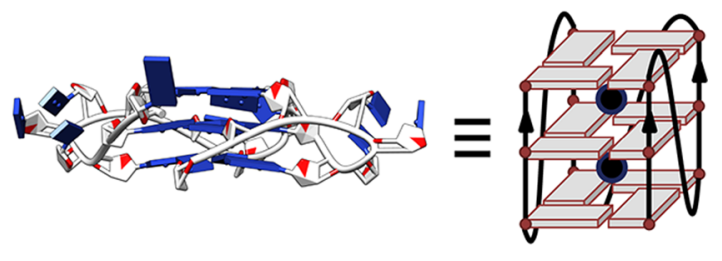

(d)

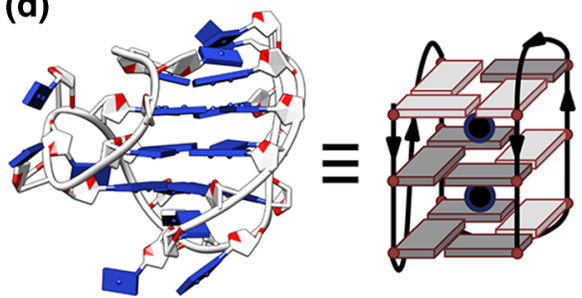

Figure 1. (a) A guanine quartet (G-quartet). (b) $X$-ray crystal structure of the parallel G-quadruplex form of $d\left(A(G G G T T A)_{3} G G G\right)$ in $\mathrm{K}^{+}$conditions [12] (PDB ID: 1KF1). (c) NMR structure of the antiparallel G-quadruplex form of d(A(GGGTTA) $\left.{ }_{3} G G G\right)$ in $\mathrm{Na}^{+}$solution [13] (PDB ID: 143D). (d) NMR structure of the hybrid G-quadruplex form of d(TT(GGGTTA) $\left.{ }_{3} G G G A\right)$ in $K^{+}$solution [15] (PDB ID: 2GKU). The schemes underline strand directionality, and base-sugar conformations (light grey for anti, dark grey for syn)

\section{$\mathrm{d}\left(\mathrm{TA}(\mathrm{GGGTTA})_{3} \mathrm{GGG}\right)[16]$, or d(TA(GGGTTA $)_{3}$ GGGTT)} [17].

Taking this high level of polymorphism into account is important to interpret experimental results obtained by different techniques, which sometimes impose using different solution conditions. G-quadruplexes are indeed often studied in different buffer conditions depending on the assay. Phosphate and Tris/ $\mathrm{HCl}$ buffers are often used to obtain neutral $\mathrm{pH}$, and are supplemented by sodium chloride or potassium chloride, usually at a concentration around $100 \mathrm{mM}$. When screening ligands towards Gquadruplexes, a sensible approach to acknowledge this polymorphism is to test ligand binding to different sequences and under a range of solution conditions. For example, ligand binding assays are often compared in $\mathrm{Na}^{+}$and in $\mathrm{K}^{+}$to probe whether a ligand has any preference for antiparallel forms (in $\mathrm{Na}^{+}$) or more parallel or hybrid forms (in $\mathrm{K}^{+}$). In indirect ligand binding assays such as changes in melting temperature, sometimes the $\mathrm{K}^{+}$concentration is decreased to 10 or even $1 \mathrm{mM}$ in order to destabilize the G-quadruplex, so as to be able to measure the effect of the ligand on the stability [18].

Mass spectrometry (MS)-based G-quadruplex drug binding assays offer several advantages compared with other traditional methods [19] because it allows direct stoichiometry observation and quantification of each peak [20]. Nevertheless, none of the buffers mentioned above are compatible with native electrospray ionization because they are nonvolatile. To bypass this limitation, ammonium acetate $\left(\mathrm{NH}_{4} \mathrm{OAc}\right)$ is used to fix the ionic strength. When Gquadruplex forming sequences are electrosprayed in
$\mathrm{NH}_{4} \mathrm{OAc}$, specific ammonium cations are retained in the complexes. They are able to coordinate between the Gquartets $[21,22]$. G-quadruplex structures made in ammonium acetate solution are, however, less stable and more polymorphic than those formed in potassium chloride solution [20].

Spraying nucleic acids in the presence of physiological cations is an important challenge that has been addressed by several groups, either for G-quadruplexes $\left(\mathrm{K}^{+}\right)$or for RNA structures $\left(\mathrm{Mg}^{2+}\right)$. Previously, Evans et al. [23] and the team of Brodbelt [24] reported tetramolecular G-quadruplexes electrosprayed with potassium adducts. In their respective works, the Gquadruplexes are preformed into potassium conditions before being partially desalted by ethanol precipitation or filtering, and resuspended in ammonium acetate for ESIMS analysis. However, although this worked well for tetramolecular G-quadruplexes that are parallel-stranded whatever the cation, for polymorphic G-quadruplexes, ammonium acetate replacement will also displace the conformational equilibria. McLuckey's group exploited ionmolecule reactions, and used vaporized acetic or formic acid inside the desolvation cell to displace metal counter-ions that stick to the phosphate groups [25]. This method allowed keeping native species in solution because the interaction with the acid is made in the gas phase and not in the solution phase. However, gas-phase structures may be disrupted. Fabris' group exploited ion-ion reactions in FTICR-MS to clean up sodium and magnesium adducts from diverse DNA and RNA structures [26]. However these approaches are not practical on an everyday basis and require specialized instrumentation. 
Here, we show that trimethylammonium acetate (TMAA) can advantageously replace ammonium acetate $\left(\mathrm{NH}_{4} \mathrm{OAc}\right)$ to carry out ESI-MS experiments on Gquadruplexes in the presence of $\mathrm{K}^{+}$. The key idea is that the trimethylammonium cation is too bulky to coordinate between quartets, and that only $\mathrm{K}^{+}$can fill the inter-quartet sites. A similar approach was used by Gray and Chaires for solution spectroscopy-monitored G-quadruplex titrations by $\mathrm{KCl}$ in the presence of tetrabutylammonium phosphate [27]. Trialkylamines or trialkylammonium buffers are commonly used in ESI-MS. In 1994, Bischoff's group compared the efficiency of triethylamine (TEA), trimethylamine (TMA), and $\mathrm{NH}_{4} \mathrm{OAc}$ to remove sodium adducts on oligomers from 12- to 132-mer oligonucleotides [28]. They showed that ammonium acetate is the least efficient in reducing the amount of adducts. Ostrander's group [29] proposed the triethylammonium acetate (TEAA) additive to clean up their mass spectra from sodium and potassium adducts. In their case, they fixed the $\mathrm{pH}$ to 7 thanks to imidazole. Lemaire et al. [30] also reported that triethylammonium bicarbonate is useful to study proteins and proteins complexes under non-denaturing conditions. They showed a charge state displacement to lower charges induced by this additive, and were able to distinguish NADH adducts on the dimer made by two alcohol dehydrogenase. The present study shows for the first time the advantage of using TMAA for studying nucleic acids by electrospray mass spectrometry in native conditions (neutral $\mathrm{pH}$, physiological ionic strength, and with sufficient amounts of $\mathrm{KCl}$ to form presumably native G-quadruplex structures).

\section{Experimental}

\section{Materials}

Oligonucleotides were purchased lyophilized and RP-cartridge purified from Eurogentec (Seraing, Belgium). In this work, the following nomenclature will be used: the hybrid G-quadruplex forming sequence $\mathrm{d}\left(\mathrm{TT}(\mathrm{GGGTTA})_{3} \mathrm{GGGA}\right)=$ 24TTG; the hybrid G-quadruplex forming sequence $\mathrm{d}\left(\mathrm{TA}(\mathrm{GGGTTA})_{3} \mathrm{GGG}\right)=23 \mathrm{TAG}$; a 22 -mer control oligonucleotide with twelve guanines but incapable of forming a G-quadruplex: d(GGG-ATG-CGA-CAG-AGA-GGA-CGG$G)=22$ non-G4; a tetramolecular parallel G-quadruplex made by four $\mathrm{d}(\mathrm{TGGGGT})$ strands $=\mathrm{TG}_{4} \mathrm{~T}$; and a bimolecular $\mathrm{G}$ quadruplex made by two d(GGGGTTTTGGGG) strands= $\mathrm{G}_{4} \mathrm{~T}_{4} \mathrm{G}_{4}$. Stock solutions were first prepared at 0.5 to $1 \mathrm{mM}$ in water. The stock concentrations were determined by UV absorbance at $260 \mathrm{~nm}$, with extinction coefficients calculated using Cavaluzzi-Borer Correction [31], and measured on an Agilent Cary 100 UV spectrophotometer. Water was nuclease-free grade from Ambion (Applied Biosystems, Lennik, Belgium). Ammonium acetate $\left(\mathrm{NH}_{4} \mathrm{OAc}\right.$, Ultra for Molecular Biology, Fluka), trimethylammonium acetate (TMAA, Ultra for UPLC, Fluka), potassium ( $\mathrm{KCl}$, $>99.999 \%$, Sigma) and sodium chloride $(\mathrm{NaCl},>99.999 \%$, Sigma) were purchased from Sigma-Aldrich (Saint-Quentin
Fallavier, France). The solutions were prepared at room temperature (no annealing), 2 to $3 \mathrm{~h}$ before the circular dichroism (CD) or MS measurements were performed. Some measurements were repeated after $1 \mathrm{wk}$, and no change in $\mathrm{CD}$ or MS results was observed. The $\mathrm{pH}$ of TMAA and DNA-containing TMAA solutions was in the 6.7-6.8 range. TMAA solution was therefore always used as received without complementary $\mathrm{pH}$-adjustment.

\section{Mass Spectrometry (MS)}

All mass spectra were obtained in negative ion mode with injection concentrations of $5 \mu \mathrm{M}$ in G-quadruplexes and $5 \mu \mathrm{M}$ internal standard $\mathrm{dT}_{6}$. Native electrospray mass spectra of oligonucleotides were obtained using several instruments, with similar results. (1) On an LCT Premier mass spectrometer (Waters, Manchester, UK), the ESI source voltage was set to $2.2 \mathrm{kV}$ with a desolvation temperature of $60^{\circ} \mathrm{C}$. Unless otherwise mentioned, the ion guide 1 voltage is $50 \mathrm{~V}$. The source pressure was increased to 35 mbar. This pressure is measured using a Center Two probe (Oerlikon Leybold Vacuum, Cologne, Germany). The syringe injection flow was fixed to $200 \mu \mathrm{L} / \mathrm{h}$. In all experiment $5 \mu \mathrm{M} \mathrm{dT} 6$ (monoisotopic mass $1762.318 \mathrm{Da}$ ) was used as internal standard. (2) An Exactive ESI-Orbitrap mass spectrometer (Thermo Scientific, Bremen, Germany) was also used to monitor the titration of $\mathrm{TG}_{4} \mathrm{~T}$ by $\mathrm{KCl}$. In this case, ESI spray voltage and capillary voltage are $2.75 \mathrm{kV}$ and $-20 \mathrm{~V}$, respectively. Capillary temperature is set to $150^{\circ} \mathrm{C}$. Tube lens and skimmer voltage are fixed to $-180 \mathrm{~V}$ and $-10 \mathrm{~V}$. In order to help the desolvation process to occur, the HCD cell voltage is set to $10 \mathrm{eV}$ and the cell pressure is $2.5 \times 10^{-5}$ mbar.

\section{Ion Mobility Spectrometry (IMS)}

The collision cross sections of $\mathrm{NH}_{4}{ }^{+}$-containing and $\mathrm{K}^{+}$containing G-quadruplexes were determined using a Synapt G2S mass spectrometer (Waters, Manchester, UK). The electrospray capillary was at $2.04 \mathrm{kV}$, the source and desolvation temperatures were $30^{\circ} \mathrm{C}$ and $40^{\circ} \mathrm{C}$, respectively, and the sampling cone was at $28 \mathrm{~V}$. The trap and transfer collision energies were 2 and $4 \mathrm{~V}$, respectively. All these parameters ensured minimal fragmentation outside the IMS cell. The helium gas flow in the pre-IMS cell was $200 \mathrm{~mL} / \mathrm{min}$, and the nitrogen gas flow in the IMS cell was $90 \mathrm{~mL} / \mathrm{min}$. The IMS T-wave was operated at $40 \mathrm{~V}$ and $600 \mathrm{~m} / \mathrm{s}$. The CCS was calibrated following the procedure of Ruotolo et al. [32] using $\mathrm{dT}_{6}{ }^{2-}\left(306 \AA^{2}\right), \mathrm{dT}_{6}{ }^{3-}\left(333 \AA^{2}\right),\left[\mathrm{dTG}_{4} \mathrm{~T}\right]_{4}^{4-}\left(730 \AA^{2}\right)$, $\left[\mathrm{dTG}_{4} \mathrm{~T}\right]_{4}{ }^{5-}\left(775 \AA^{2}\right)$ [33], and $\left[\mathrm{dTG}_{4} \mathrm{~T}\right]_{4}{ }^{6-}\left(795 \AA^{2}\right)$. These five collision cross sections were measured in a helium drift tube mass spectrometer [34]. For the telomeric Gquadruplexes, collision activation upon entrance in the IMS cell is promoted by changing the trap DC bias from 18 to $30 \mathrm{~V}$. The helium cell DC is $30.2 \mathrm{~V}$ and the IMS DC entrance is $7.3 \mathrm{~V}$. 


\section{Circular Dichroism (CD)}

$\mathrm{CD}$ experiments were performed to obtain information on the DNA strands orientation. Experiments were run on a Jasco J-815 spectrophotometer using a quartz cell of $2 \mathrm{~mm}$ path length. All spectra shown here are the sum of three scans, acquired at $20^{\circ} \mathrm{C}$ with a scan speed of $50 \mathrm{~nm} / \mathrm{min}$ and a $2 \mathrm{~nm}$ bandwidth. The $\mathrm{CD}$ data were normalized to molar circular-dichroic absorption $(\Delta \varepsilon)$ based on DNA concentration using the following Equation,

$\Delta \varepsilon=\frac{\theta}{32980 \times c \times l}$

where $\theta$ is the $\mathrm{CD}$ ellipticity in milidegrees, $c$ is DNA concentration in mol L ${ }^{-1}\left(5 \times 10^{-6} \mathrm{~mol} . \mathrm{L}^{-1}\right)$, and $l$ is the pathlength in $\mathrm{cm}(0.2 \mathrm{~cm})$.

\section{Results and Discussions}

G-Quadruplexes from TMAA/KCl Solutions Show a Specific Number of $K^{+}$Adducts Corresponding to Coordination Between the G-Quartets

The mass spectrometer is tuned so that when the ion guide 1 is $50 \mathrm{~V}$, the native structure is kept in the gas phase, as tested with the sensitive G-quadruplex $\left[\mathrm{dG}_{4} \mathrm{~T}_{4} \mathrm{G}_{4}\right]_{2}$ in $100 \mathrm{mM}$ $\mathrm{NH}_{4} \mathrm{OAc}$ (Supporting information S1) [22]. Figure 2a shows a mass spectrum of the human telomeric sequence 23TAG in $100 \mathrm{mM} \mathrm{NH} \mathrm{N}_{4} \mathrm{OAc}$ in native conditions (low ion guide 1 voltage: $50 \mathrm{~V}$ ) (Figure 2a, top). G-quadruplexes chelating two ammonium cations constitute the most abundant species, but a distribution of adducts is nevertheless observed (from 0 up to 5 or 6 ammonium cations). If the structure was unknown, it would actually be difficult to conclude on the preferred ammonium binding stoichiometry, as there is no clear bias in the ammonium ion distribution at any voltage. When the ion guide 1 voltage is increased from 50 to $70 \mathrm{~V}$ (Figure 1a, bottom) the complex is disrupted, the ammonium ions are released as $\mathrm{NH}_{3}$ and the most abundant species becomes the free oligonucleotide.

In order to examine the effect of adding potassium to the solution, we doped the ammonium acetate solution by $1 \mathrm{mM}$ potassium chloride (Figure 2b). In these conditions, the resulting mass spectra are noisy at low $\mathrm{m} / \mathrm{z}$ range (not shown) due to clusters formation, and there are numerous adducts on the G-quadruplexes peaks. As only two specifically bound $\mathrm{K}^{+}$ions are anticipated, additional adducts are therefore nonspecific external adducts. Therefore, in ammonium acetate solutions doped with $\mathrm{KCl}$, it is not possible to deduce the number of specifically bound potassium ions in the G-quadruplexes. Besides, two series of peaks are observed at low source voltage, indicating that each inter-quartet binding site may be occupied either by $\mathrm{NH}_{4}{ }^{+}$or by $\mathrm{K}^{+}$.

To drive $\mathrm{K}^{+}$ions to occupy inter-quartet sites specifically, we used trimethylammonium acetate (TMAA) as volatile (a)

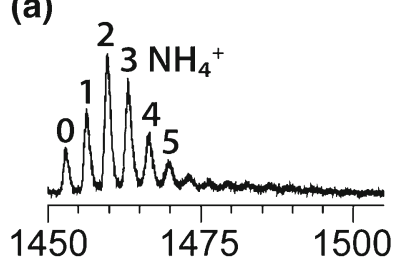

(b)

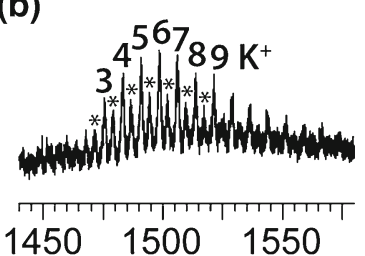

145

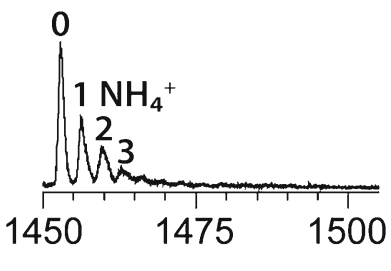

(c)

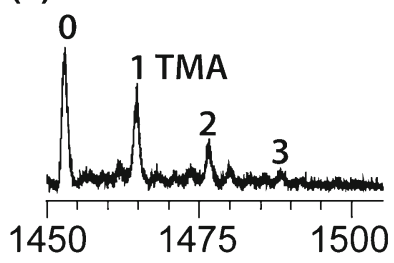

(d)
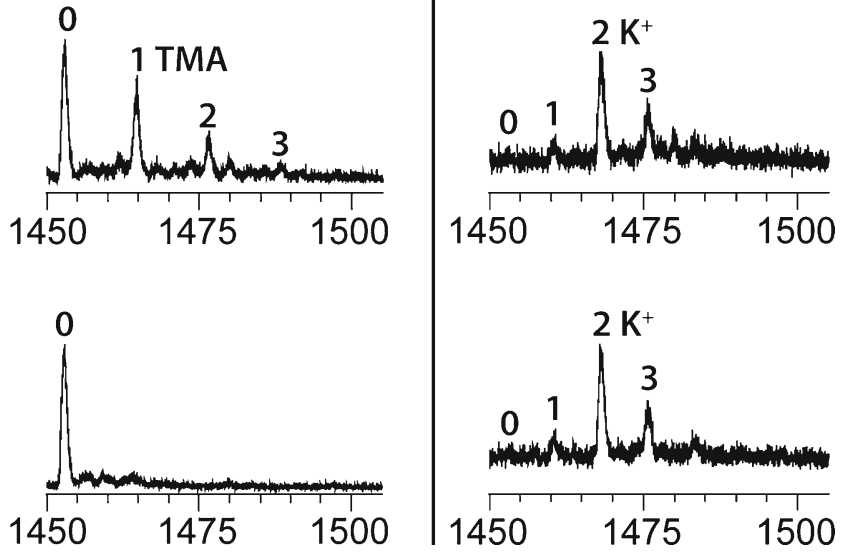

Figure 2. ESI-MS of $5 \mu \mathrm{M} 23 \mathrm{TAG}$ into (a) $100 \mathrm{mM} \mathrm{NH}_{4} \mathrm{OAc}$, (b) $100 \mathrm{mM} \mathrm{NH}_{4} \mathrm{OAc}+1 \mathrm{mM} \mathrm{KCl}$, (c) $100 \mathrm{mM}$ TMAA, and (d) $100 \mathrm{mM} \mathrm{TMAA}+1 \mathrm{mM} \mathrm{KCl}$. The top mass spectra were recorded with an ion guide 1 voltage of $50 \mathrm{~V}$ and the bottom ones with $70 \mathrm{~V}$. The annotations represent the number of adducts on the 5- charge state. The peak series with stars corresponds to mixed $\mathrm{NH}_{4}{ }^{+} / \mathrm{K}^{+}$adducts

buffer. ESI-MS recorded in TMAA alone show predominantly no TMA adduct (Figure 2c), in line with the fact that the trimethylammonium cation is too bulky to fit between Gquartets. At low ion guide 1 voltage ( $50 \mathrm{~V}$, top) some TMA adducts can be observed but the shape of the distribution is typical of nonspecific adducts. This was confirmed with a control single strand incapable of forming a Gquadruplex in solution (Supporting Information S2). When the ion guide 1 voltage is set to $70 \mathrm{~V}$ (bottom) the only resulting peak is the DNA alone.

Figure 2d shows 23TAG electrosprayed in TMAA doped by $1 \mathrm{mM} \mathrm{KCl}$. The most abundant species is the Gquadruplex chelating 2 potassium cations. This stoichiometry was expected because the structure adopted by $23 \mathrm{TAG}$ contains three G-quartets, and because $\mathrm{K}^{+}$specific binding sites are located between quartets, there are two potassium binding sites per G-quadruplex. When the voltage is 
increased to $70 \mathrm{~V}$, the remaining trimethylammonium (TMA) adducts are expelled, but the $\mathrm{K}^{+}$adduct distribution remains identical, and clearly biased towards the $2-\mathrm{K}^{+}$ adduct. The monovalent ion binding stoichiometry can be obtained with much more confidence in the TMAA/KCl conditions, and evidence of intramolecular G-quadruplex formation can be concluded with more confidence than in pure $\mathrm{NH}_{4} \mathrm{OAc}$.

\section{TMAA Suppresses Nonspecific Alkali Adducts More Efficiently than $\mathrm{NH}_{4} \mathrm{OAc}$, Including in Native Conditions}

The comparison between Figure $2 \mathrm{~b}$ and $\mathrm{d}$ illustrates that using TMAA instead of $\mathrm{NH}_{4} \mathrm{OAc}$ as electrolyte at $\mathrm{pH}=7$ allows the elimination of undesirable nonspecific $\mathrm{K}^{+}$ adducts. This may be due to the fact that the trimethylammonium ion has greater affinity than ammonium ion for the external nonspecific binding sites, so that it is more efficient in competing with alkali cations. To test that hypothesis, we investigated the effect of the TMAA concentration on potassium and sodium adducts in the 24TTG human telomeric sequence (Figure 3). For all tested TMAA concentration $(50 \mathrm{mM}$, Figure $3 \mathrm{a} ; 100 \mathrm{mM}$, Figure $3 \mathrm{~b}$, and $150 \mathrm{mM}$, Figure $3 \mathrm{c}$ ) in the case of potassium the most abundant species is the G-quadruplex with two
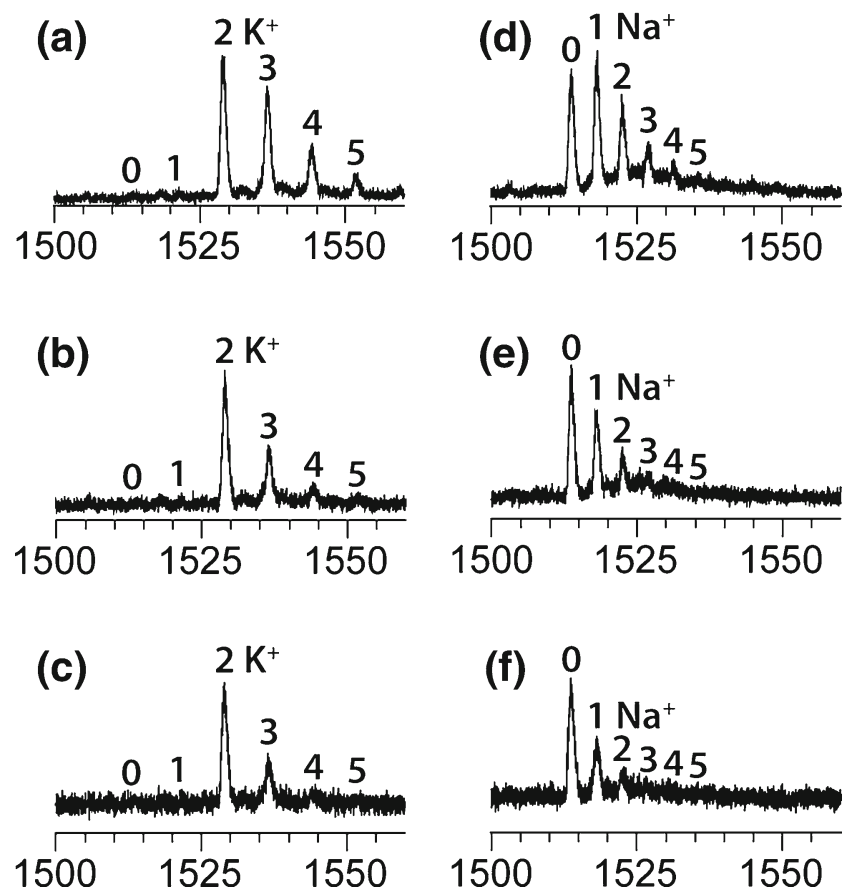

Figure 3. ESI-MS of $5 \mu \mathrm{M} 24 \mathrm{TTG}$ into increasing amount of TMAA. Left: $1 \mathrm{mM} \mathrm{KCl}$ with (a) $50 \mathrm{mM}$, (b) $100 \mathrm{mM}$, and (c) $150 \mathrm{mM}$ TMA, respectively. Right: $1 \mathrm{mM} \mathrm{NaCl}$ with (d) $50 \mathrm{mM}$, (e) $100 \mathrm{mM}$, and (f) $150 \mathrm{mM}$ TMA, respectively. Mass spectra were recorded with an ion guide 1 voltage of $70 \mathrm{~V}$. The annotations represent the potassium (a)-(c) or sodium (d)-(f) adducts on the 5 - charge state potassium cations. What changes is the number of additional, nonspecific $\mathrm{K}^{+}$adducts. When TMAA concentration is increased, nonspecific adducts are increasingly suppressed to give almost exclusively the Gquadruplex with 2 potassium ions.

In the case of sodium (Figure 3d, e, and f), the same effect was observed. However the final distribution is biased towards zero $\mathrm{Na}^{+}$adduct, suggesting that no G-quadruplex is formed. This was confirmed by CD spectroscopy (Figure 4 and section below). The nonspecific adduct suppression effect was also confirmed with other DNA structures (see Supporting Information S3). The maximum $\mathrm{KCl}$ or $\mathrm{NaCl}$ concentration amenable to electrospray in $100 \mathrm{mM}$ TMAA is about $1 \mathrm{mM}$. Above this concentration the signal/noise ratio decreases significantly and the formation of clusters at lower $\mathrm{m} / \mathrm{z}$ becomes predominant. This concentration is sufficient for potassium, but not sodium, to induce the formation of the G-quadruplexes studied here. The lesser affinity of the G-quadruplexes for sodium than for potassium is well documented [35]. The remaining portion of the present paper focuses on G-quadruplexes formed in potassium conditions.

Besides displacing nonspecific adducts, increasing the TMAA concentration has also another effect: the charge states are displaced to lower values (Supporting Information S4). The lower charge states presented more numerous nonspecific adducts than the 5- presented here. Keeping the

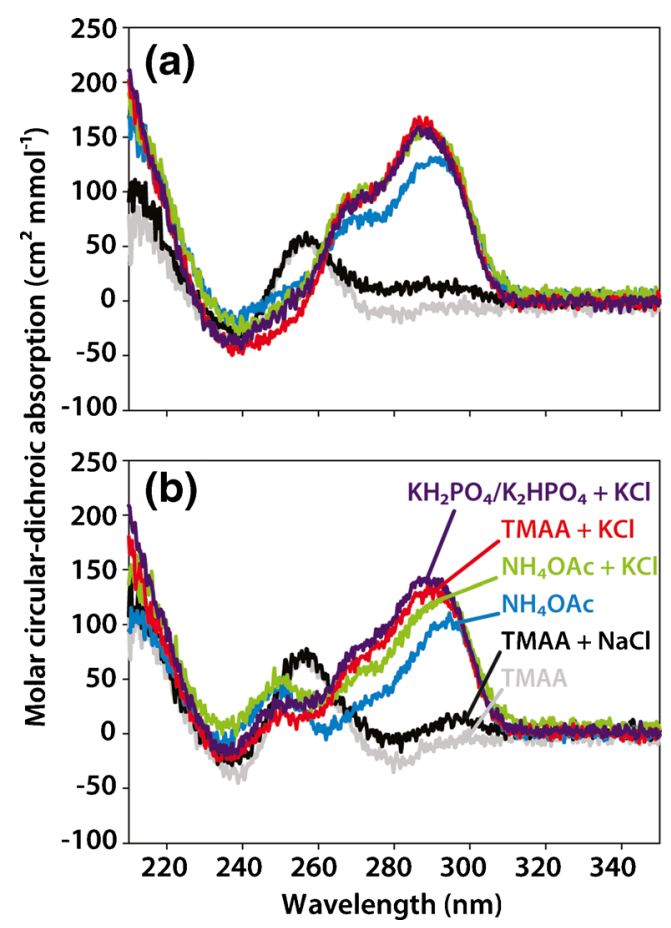

Figure 4. CD spectra of $5 \mu \mathrm{M} 24 \mathrm{TTG}$ (a) and 23TAG (b) in different solution conditions (see also annotation in panel (b): $20 \mathrm{mM} \mathrm{KH} \mathrm{PO}_{4} / \mathrm{K}_{2} \mathrm{HPO}_{4}+70 \mathrm{mM} \mathrm{KCl}$ at $\mathrm{pH} 7$ (purple), in $100 \mathrm{mM} \mathrm{NH}_{4} \mathrm{OAc}$ (blue), in $100 \mathrm{mM} \mathrm{NH}_{4} \mathrm{OAc}+1 \mathrm{mM} \mathrm{KCl}$ (green), in $100 \mathrm{mM}$ TMAA (grey), in $100 \mathrm{mM} \mathrm{TMAA}+1 \mathrm{mM}$ $\mathrm{KCl}$ (red), or in $100 \mathrm{mM} \mathrm{TMAA}+1 \mathrm{mM} \mathrm{NaCl}$ (black) 
TMAA concentration at $100 \mathrm{mM}$ allowed a good compromise to determine stoichiometry thanks to 5- charge state without losing too much signal. Triethylammonium acetate (TEAA) was also tested because it was reported to displace alkali ions even better than TMAA [28]. However, TEAA displaced totally the charge state 5- to 4-, and the adduct suppression effect of TEAA was less efficient on the 4charge state than TMAA on the 5- charge state (data not shown). TMAA is the best compromise to obtain clean ESI mass spectra at low ion internal energies, which is important to preserve the gas-phase structure (see below).

\section{The G-Quadruplex Structures Formed in $100 \mathrm{mM}$ TMAA+1 $\mathrm{mM} \mathrm{KCl}$ Are Similar to Those Formed in $100 \mathrm{mM} \mathrm{KCl} /$ Phosphate Buffer}

To check whether the structures of the G-quadruplexes formed in TMAA/ $\mathrm{KCl}$ are closer to those formed in pure $\mathrm{NH}_{4} \mathrm{OAc}$ or in pure $\mathrm{KCl}$, circular dichroism (CD) spectroscopy was used. This technique is sensitive to the orientation of the strands in G-quadruplexes studies [36]: a maximum at $260 \mathrm{~nm}$ and a minimum at $240 \mathrm{~nm}$ indicate the presence of parallel G-quadruplex with homo-stacking between all-anti guanine quartets. A maximum at $290 \mathrm{~nm}$ and a minimum at $260 \mathrm{~nm}$ indicate the presence of antiparallel G-quadruplex with alternate syn-anti guanine stacking motifs. Hybrid Gquadruplexes will show two maximum peaks at 260 and $290 \mathrm{~nm}$, as they possess both types of stacking. A mixture of structures in solution will result in a CD spectrum containing the weighted average of each contribution.

In Figure 4, we compare the CD spectra of the human telomeric DNA sequences in ammonium acetate, in phosphate buffer conditions $\left(20 \mathrm{mM} \mathrm{KH} \mathrm{PO}_{4} / \mathrm{K}_{2} \mathrm{HPO}_{4}+70 \mathrm{mM}\right.$ $\mathrm{KCl}$, the buffer in which the NMR structures were determined), and in the different solution compositions tested here by ESI-MS (24TTG, Figure 4a and 23TAG, Figure $4 \mathrm{~b}$ ). The fact that the structures differ in $\mathrm{KCl}$ and in $\mathrm{NH}_{4} \mathrm{OAc}$ (Figure 4, purple and blue, respectively) was already known [20]. The structure of G-quadruplexes formed in ammonium acetate are generally intermediate between the ones formed in $\mathrm{KCl}$ (predominant in the nucleus) [37] and in $\mathrm{NaCl}$ [20].

In TMAA without $\mathrm{KCl}$ (Figure 4, grey), both DNA sequences adopt the same kind of $\mathrm{CD}$ spectra, characteristic of unfolded DNA. When $1 \mathrm{mM} \mathrm{NaCl}$ is added to TMAA (Figure 4, black), the species remains unfolded, confirming the anticipation from the absence of specific $2-\mathrm{Na}^{+}$adduct observed in the MS experiments in the same conditions (Figure 3e). However, when $1 \mathrm{mM} \mathrm{KCl}$ is added in the TMAA solution (Figure 4, red) the G-quadruplexes formed adopt almost exactly the same $\mathrm{CD}$ spectra as the ones in the phosphate buffer conditions. KCl-doped ammonium acetate solutions (Figure 4, green) showed CD spectra closer to the purely $\mathrm{KCl}$ form, but not as close as the $\mathrm{KCl}$-doped TMAA conditions. In conclusion, the $100 \mathrm{mM}$ TMAA/ $1 \mathrm{mM} \mathrm{KCl}$ conditions are compatible with electrospray mass spectrom- etry and favor the formation of structures that possess almost identical proportion of homo-stacking versus alternate stacking as in $100 \mathrm{mM} \mathrm{K}{ }^{+}$solutions. Further studies, for example by NMR in deuterated TMAA, will be needed to determine if the structures are indeed identical.

\section{Ion Mobility Spectrometry Experiments Indicate a Similar Shape for Telomeric G-Quadruplexes Preserving Two $\mathrm{K}^{+}$or $\mathrm{NH}_{4}^{+}$}

In MS experiments on G-quadruplex in $\mathrm{NH}_{4} \mathrm{OAc}$, ammonium ion preservation in the gas phase structure is believed to ensure the preservation of the solution-phase structure [22, 38]. Is that the same in the case of $\mathrm{K}^{+}$ions? To probe the gas-phase structure of the G-quadruplexes, we used ion mobility spectrometry coupled to mass spectrometry (IMSMS). This experiment links the arrival time of an ion inside the mobility cell to a shape factor called collision cross section (CCS). Figure 5 shows the results: two conditions are compared, $100 \mathrm{mM}$ TMAA $+1 \mathrm{mM} \mathrm{KCl}$ (red) and $100 \mathrm{mM} \mathrm{NH} \mathrm{NH}_{4} \mathrm{OAc}$ (brown and blue) for the sequence 24TTG. Very similar results were obtained for 23TAG (Supporting Information S5). The top graphs show the results for the 6- charge state [TMAA/ $\mathrm{KCl}$ in (A), $\mathrm{NH}_{4} \mathrm{OAc}$ in (B)] and the bottom graphs are for the 5- ions. The bias voltage right before the mobility cell entrance was varied $(18 \mathrm{~V}, 25 \mathrm{~V}$, or $30 \mathrm{~V})$. The $\mathrm{NH}_{4}{ }^{+}$-binding stoichiometries vary with the bias voltage, in a similar way as they vary with source voltages (see Figure 2 and discussion thereof). For that reason, we represented the integrated CCS of all adduct species $\left(0,1\right.$, and $2 \mathrm{NH}_{4}^{+}$adducts summed, in brown, and the CCS integrated only over the mass spectral peak corresponding to two $\mathrm{NH}_{4}^{+}$ions bound (blue). CCS distributions were normalized to their total area in order to reflect the proportion of folded or unfolded G-quadruplexes with two ammonium ions.

At low bias voltage $(18 \mathrm{~V})$ the CCSs were similar in both conditions: one peak around $800 \AA^{2}$ for $24 \mathrm{TTG}$ for the 6ions (Figure 5a and b). For the 5- ions (Figure $5 c$ and d) the CCS peak appears at smaller values; which is typical in ion mobility spectrometry because the overall structure is less charged and then less dilated. In native conditions, the structures are very close in term of CCS in $\mathrm{NH}_{4}{ }^{+}$(light brown) or $\mathrm{K}^{+}$(light red). Interestingly, the Gaussian curve that fits the data is a little bit broader in ammonium ion conditions. This can be due to a greater floppiness or to a greater polymorphism in ammonium ion solution. When the bias voltage increases (from light to dark colors) the peaks at the initial CCS value decrease and at the expense of peaks at higher CCS (for 6- charge state) or lower CCS (for 5- charge state). Expansion of high charge states and compaction of lower charge states upon energy increase was noted for other G-quadruplexes in ammonium conditions [38].

In the case of ammonium ions, the gas-phase structure is changing when the voltage is increased, and ammonia loss observed in the mass spectra gives a hint that denaturation 
(a)
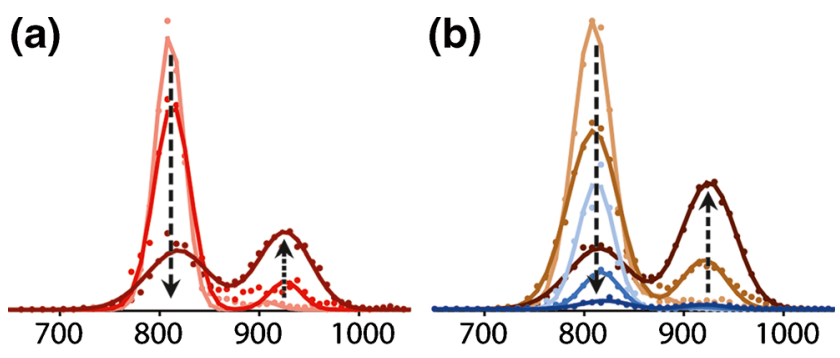

(c)

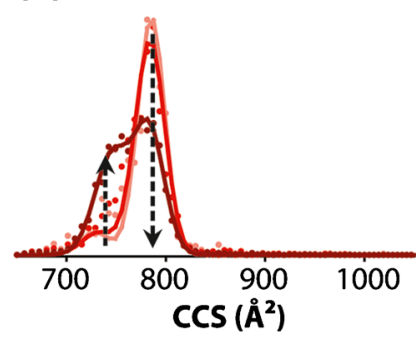

(d)

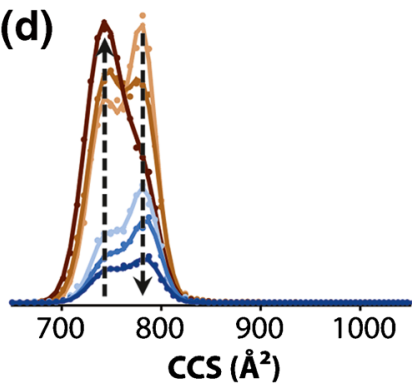

$\equiv$ All $\mathrm{NH}_{4}^{+}$

$\equiv 2 \mathrm{NH}_{4}^{+}$

Figure 5. Collision cross section distribution of $5 \mu \mathrm{M} 24 \mathrm{TTG}$ into $100 \mathrm{mM} \mathrm{TMAA}+1 \mathrm{mM} \mathrm{KCl}$ (a) and (c) or $100 \mathrm{mM}$ $\mathrm{NH}_{4} \mathrm{OAc}$ (b) and (d). (a) and (b) represent the 6- ions and (c) and (d) the 5- ions. Bias voltage increases from light to dark colors $(18,25$, and $30 \mathrm{~V}$, respectively). Brown colors represent the collision cross section reconstructed from the sum of the G-quadruplexes with zero, one, and two ammonium cations and blue ones are the collision cross section of the G-quadruplexes with two ammonium ions exclusively. Red colors are the G-quadruplexes with two potassium ions

happens in the gas phase. When two potassium ions are trapped inside the G-quadruplex formed from TMAA/ $\mathrm{KCl}$, the collisional activation has the same unfolding effect, although the potassium ion adducts are not lost. Therefore, although the voltage at which unfolding occurs is higher in the presence of potassium than ammonium, gas-phase unfolding still occurs. Importantly, these changes in ATD are not accompanied by visible changes in the mass spectra for the TMAA/ $\mathrm{KCl}$ conditions: the $\mathrm{K}^{+}$ions cannot escape from the multiply charged anions.

\section{The $\mathrm{KCl}$ Concentration Required for G-Quadruplex Formation in TMAA Depends on the Sequence}

Above, we showed results with the maximum concentration we could electrospray while keeping clean mass spectra (1 $\mathrm{mM})$. Here we describe $\mathrm{KCl}$ titration experiments that probe the minimum $\mathrm{KCl}$ concentration required to fold the G-quadruplexes. Figure 6 shows two $\mathrm{KCl}$ titrations in $100 \mathrm{mM}$ TMAA for the intramolecular telomeric sequence 23TAG (Figure 6a) and for the tetramolecular G-quadruplex $\left[\mathrm{dTG}_{4} \mathrm{~T}\right]_{4}$ (Figure 6b). At $100 \mu \mathrm{M} \mathrm{KCl,} \mathrm{23TAG} \mathrm{G-}$ quadruplexes are not formed: only a very small amount of potassium adducts are observed. When the $\mathrm{KCl}$ concentration is increased, the adduct distribution is shifted towards

two potassium ions bound. Mass spectra at 200 and $300 \mu \mathrm{M}$ unambiguously demonstrate cooperativity in $\mathrm{K}^{+}$binding: the cation adducts distribution is non-statistical and depleted in $1-\mathrm{K}^{+}$adduct. This is very important to understand the folding mechanism of G-quadruplexes, and mass spectrometry experiments allow to unambiguously visualize the concerted incorporation of two potassium ions.

The second example is the titration of the single strand $\mathrm{dTG}_{4} \mathrm{~T}$, which forms a tetramolecular G-quadruplex with three coordinated monovalent ions. The titration is made on a lower concentrations range, as the G-quadruplex formation is already complete at $80 \mu \mathrm{M}$ in $\mathrm{KCl}$. Despite the fact that ammonium ions were not added intentionally, some ammonium adducts appear here at low $\mathrm{KCl}$ concentrations, and mixed $\mathrm{NH}_{4}{ }^{+} / \mathrm{K}^{+}$adducts appear at intermediate $\mathrm{KCl}$ concentrations (the sum of adducts always being three cations, i.e., one between each G-quartet). Ammonium traces come from the oligonucleotide synthesis and, therefore, traces of ammonium-ion bound tetramers are preformed in the lyophilized oligonucleotides. However the single strand is prevalent (see full scale mass spectra in the Supporting Information S6). (a)

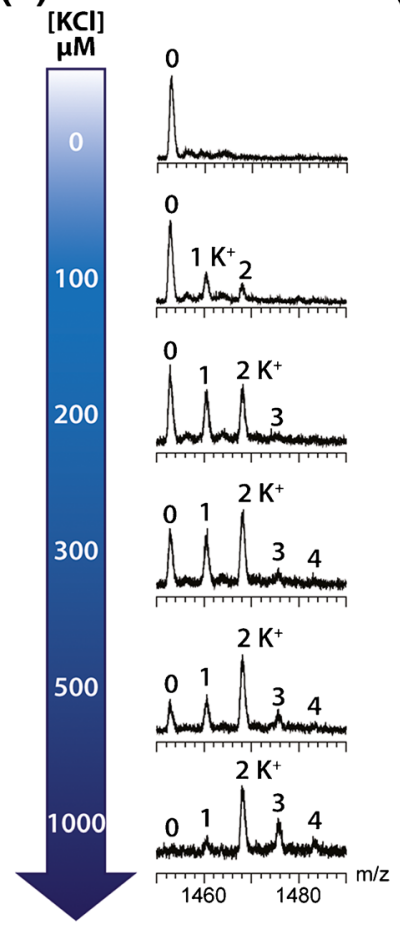

(b)

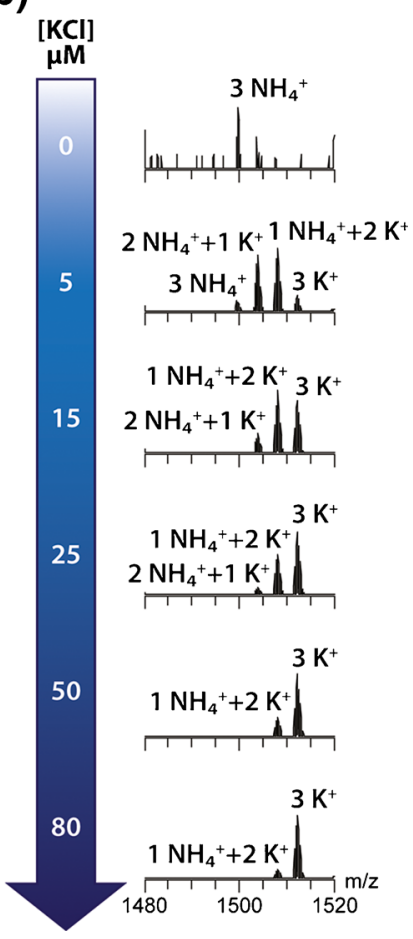

Figure 6. $\mathrm{KCl}$ titration of (a) $5 \mu \mathrm{M}$ 23TAG and (b) $20 \mu \mathrm{M}$ $\mathrm{TG}_{4} \mathrm{~T}$ single strand into $100 \mathrm{mM}$ TMAA. The annotations indicate the number of adducts on the 5- charge state. In titration (a), the single strand was allowed to react for $4 \mathrm{~h}$ at room temperature before the mass spectra were recorded using the LCT mass spectrometer. In titration (b), the solutions were prepared with $100 \mu \mathrm{M}$ in $\mathrm{TG}_{4} \mathrm{~T}$ single strand for $24 \mathrm{~h}$ before being diluted to $20 \mu \mathrm{M}$, and the mass spectra were recorded on the Exactive mass spectrometer 
The mechanism of formation of the tetramolecular Gquadruplex formation is very different from the formation of the intramolecular quadruplex. Adding a very small amount of potassium into the solution induced the cooperative tetramerization of $\mathrm{TG}_{4} \mathrm{~T}$. To be stabilized, the tetramer must always contain total of three cations in its central channel. Then, because potassium has a higher affinity for Gquadruplexes than ammonium, the equilibrium is displaced specifically towards the $3-\mathrm{K}^{+}$adduct by addition of higher $\mathrm{KCl}$ amounts. This example further illustrates the correlation between the observation of $n \mathrm{~K}^{+}$adducts and the presence of $n+1$ G-quartets [21].

\section{Conclusions}

We reported here for the first time that by using trimethylammonium acetate (TMAA) as electrolyte, electrospray mass spectra of G-quadruplexes can be obtained in the presence of the likely physiologically relevant potassium cation. Moreover, circular dichroism experiments indicate that the guanine stacking motifs and, therefore, relative strand orientations are very similar in $100 \mathrm{mM}$ TMAA/ $/ \mathrm{KCl}$ and $100 \mathrm{mM} \mathrm{KCl}$, so the presence of TMAA in the ESI-MS compatible solution does not affect the overall structure of the DNA G-quadruplexes studied here. This is particularly important for polymorphic G-quadruplexes such as those formed by the human telomeric sequence. Also, our conditions make it easier to determine the number of potassium ions specifically coordinated to the structure and, hence, to ascertain the presence of a G-quadruplex in solution and how many G-quartets are involved.

The perspectives open by the present work are numerous. First, as in TMAA $/ \mathrm{KCl}$ solutions the $\mathrm{K}^{+}$-binding stoichiometry is determined easily. In $\mathrm{NH}_{4} \mathrm{OAc}$ conditions, the ESIMS determination of cation binding stoichiometry was clear only for parallel G-quadruplexes, which robustly preserved their ammonium ions in the gas phase, whereas the antiparallel structures did not. The new method can be used to probe the number of specific binding sites in other sequences, for example issued from bioinformatics studies. Second, as TMAA allows spraying potassium-bound Gquadruplexes in soft conditions, this opens the way to probing preserved structures in the gas phase, as shown by our preliminary experiments with ion mobility spectrometry. Third, the TMAA/ $\mathrm{KCl}$ conditions are interesting for ligand screening, in order to test the binding stoichiometry and affinity for potassium-bound structures. ESI-MS can also be used to understand the G-quadruplex folding mechanism and, more specifically, the interplay between cation binding and folding. Detailed investigation of the folding of various human telomeric sequences upon $\mathrm{K}^{+}$or ligand titration is currently under way in our laboratory. Finally, it would be interesting to test whether the use of TMAA can be extended to other systems than DNA G-quadruplexes, for example to RNA-magnesium complexes, or to protein complexes.

\section{Acknowledgments}

The authors thank Frédéric Rosu and Miguel Garavis for fruitful discussion, the Structural Biophysico-chemistry Platform of the IECB (CNRS UMS 3033 and Inserm US 001) for access to the MS instruments, Kevin Giles and Jonathan Williams (Waters, Manchester, UK) for assistance in performing the IMS experiments on the Synapt G2S, and Christian Bleiholder and Mike Bowers (UC Santa Barbara) the opportunity to measure the drift tube CCS of the new calibrants. This work was funded by the Inserm (ATIP-Avenir), the EU (Marie Curie CIG), and the Conseil Régional Aquitaine (Crédits d'installation). A.M. has a Ph.D. fellowship from Inserm and Conseil Régional Aquitaine.

\section{Open Access}

This article is distributed under the terms of the Creative Commons Attribution License which permits any use, distribution, and reproduction in any medium, provided the original author(s) and the source are credited.

\section{References}

1. Rankin, S., Reszka, A.P., Huppert, J., Zloh, M., Parkinson, G.N., Todd, A.K., Ladame, S., Balasubramanian, S., Neidle, S.: Putative DNA quadruplex formation within the human c-kit oncogene. J. Am. Chem. Soc. 127(6), 10584-10589 (2005)

2. Siddiqui-Jain, A., Grand, C.L., Bearss, D.J., Hurley, L.H.: Direct evidence for a G-quadruplex in a promoter region and its targeting with a small molecule to repress c-MYC transcription. Proc. Natl. Acad. Sci. U. S. A. 99(18), 11593-11608 (2002)

3. Cogoi, S., Xodo, L.E.: G-quadruplex formation within the promoter of the KRAS proto-oncogene and its effect on transcription. Nucleic Acids Res. 34(9), 2536-2549 (2006)

4. Sun, D., Guo, K., Rusche, J.J., Hurley, L.H.: Facilitation of a structural transition in the polypurine/polypyrimidine tract within the proximal promoter region of the human VEGF gene by the presence of potassium and G-quadruplex-interactive agents. Nucleic Acids Res. 33(18), 60706780 (2005)

5. Wang, Y., Patel, D.J.: Guanine residues in d(T2AG3) and d(T2G4) form parallel-stranded potassium cation stabilized G-quadruplexes with anti glycosidic torsion angles in solution. Biochemistry 31(35), 81128119 (1992)

6. Biffi, G., Tannahill, D., McCafferty, J., Balasubramanian, S.: Quantitative visualization of DNA G-quadruplex structures in human cells. Nat. Chem. 5(3), 182-186 (2013)

7. Neidle, S.: Human telomeric G-quadruplex: the current status of telomeric G-quadruplexes as therapeutic targets in human cancer. FEBS J. 277(5), 1118-1125 (2010)

8. Rodriguez, R., Muller, S., Yeoman, J.A., Trentesaux, C., Riou, J.F., Balasubramanian, S.: A novel small molecule that alters shelterin integrity and triggers a DNA-damage response at telomeres. J. Am. Chem. Soc. 130(47), 15758-15759 (2008)

9. Gomez, D., Wenner, T., Brassart, B., Douarre, C., O'Donohue, M.F., El Khoury, V., Shin-Ya, K., Morjani, H., Trentesaux, C., Riou, J.F.: Telomestatin-induced telomere uncapping is modulated by POT1 through G-overhang extension in HT1080 human tumor cells. J. Biol. Chem. 281(50), 38721-38729 (2006)

10. Phatak, P., Cookson, J.C., Dai, F., Smith, V., Gartenhaus, R.B., Stevens, M.F., Burger, A.M.: Telomere uncapping by the G-quadruplex ligand RHPS4 inhibits clonogenic tumour cell growth in vitro and in vivo consistent with a cancer stem cell targeting mechanism. Br. J. Cancer 96(8), 1223-1233 (2007)

11. Phan, A.T.: Human telomeric G-quadruplex: structures of DNA and RNA sequences. FEBS J. 277(5), 1107-1117 (2010) 
12. Parkinson, G.N., Lee, M.P., Neidle, S.: Crystal structure of paralle quadruplexes from human telomeric DNA. Nature 417(6891), 876-880 (2002)

13. Wang, Y., Patel, D.J.: Solution structure of the human telomeric repeat d[AG3(T2AG3)3] G-tetraplex. Structure 1(4), 263-282 (1993)

14. Lim, K.W., Amrane, S., Bouaziz, S., Xu, W., Mu, Y., Patel, D.J., Luu, K.N., Phan, A.T.: Structure of the human telomere in K+solution: a stable basket-type G-quadruplex with only two G-tetrad layers. J. Am. Chem. Soc. 131(12), 4301-4309 (2009)

15. Luu, K.N., Phan, A.T., Kuryavyi, V., Lacroix, L., Patel, D.J.: Structure of the human telomere in K+solution: an intramolecular $(3+1) \mathrm{G}$ quadruplex scaffold. J. Am. Chem. Soc. 128(30), 9963-9970 (2006)

16. Ambrus, A., Chen, D., Dai, J., Bialis, T., Jones, R.A., Yang, D.: Human telomeric sequence forms a hybrid-type intramolecular G-quadruplex structure with mixed parallel/antiparallel strands in potassium solution. Nucleic Acids Res. 34(9), 2723-2735 (2006)

17. Phan, A.T., Luu, K.N., Patel, D.J.: Different loop arrangements of intramolecular human telomeric $(3+1)$ G-quadruplexes in $\mathrm{K}+$ solution. Nucleic Acids Res. 34(19), 5715-5719 (2006)

18. De Cian, A., Guittat, L., Kaiser, M., Sacca, B., Amrane, S., Bourdoncle, A., Alberti, P., Teulade-Fichou, M.P., Lacroix, L., Mergny, J.L.: Fluorescence-based melting assays for studying quadruplex ligands. Methods 42(2), 183-195 (2007)

19. Yuan, G., Zhang, Q., Zhou, J., Li, H.: Mass spectrometry of Gquadruplex DNA: formation, recognition, property, conversion, and conformation. Mass Spectrom. Rev. 30(6), 1121-1142 (2011)

20. Smargiasso, N., Rosu, F., Hsia, W., Colson, P., Baker, E.S., Bowers, M.T., De Pauw, E., Gabelica, V.: G-quadruplex DNA assemblies: loop length, cation identity, and multimer formation. J. Am. Chem. Soc. 130(31), 10208-10216 (2008)

21. Gros, J., Rosu, F., Amrane, S., De Cian, A., Gabelica, V., Lacroix, L., Mergny, J.L.: Guanines are a quartet's best friend: impact of base substitutions on the kinetics and stability of tetramolecular quadruplexes. Nucleic Acids Res. 35(9), 3064-3075 (2007)

22. Balthasart, F., Plavec, J., Gabelica, V.: Ammonium ion binding to DNA G-quadruplexes: do electrospray mass spectra faithfully reflect the solution-phase species? J. Am. Soc. Mass Spectrom. 24(1), 1-8 (2013)

23. Evans, S.E., Mendez, M.A., Turner, K.B., Keating, L.R., Grimes, R.T., Melchoir, S., Szalai, V.A.: End-stacking of copper cationic porphyrins on parallel-stranded guanine quadruplexes. J. Biol. Inorg. Chem. 12(8), 1235-1249 (2007)

24. Pierce, S.E., Wang, J., Jayawickramarajah, J., Hamilton, A.D., Brodbelt, J.S.: Examination of the effect of the annealing cation on higher order structures containing guanine or isoguanine repeats. Chem. Eur. J. 15(42), 11244-11255 (2009)

25. Kharlamova, A., Prentice, B.M., Huang, T.-Y., McLuckey, S.A.: Electrospray droplet exposure to gaseous acids for reduction of metal counter-ions in nucleic acid ions. Int. J. Mass Spectrom. 300(2/3), 158166 (2011)

26. Turner, K.B., Monti, S.A., Fabris, D.: Like polarity ion/ion reactions enable the investigation of specific metal interactions in nucleic acids and their noncovalent assemblies. J. Am. Chem. Soc. 130(40), 1335313363 (2008)

27. Gray, R.D., Chaires, J.B.: Isothermal folding of G-quadruplexes. Methods 57(1), 47-55 (2012)

28. Potier, N., Van Dorsselaer, A., Cordier, Y., Roch, O., Bischoff, R.: Negative electrospray ionization mass spectrometry of synthetic and chemically modified oligonucleotides. Nucleic Acids Res. 22(19), 3895-3903 (1994)

29. Deguchi, K., Ishikawa, M., Yokokura, T., Ogata, I., Ito, S., Mimura, T., Ostrander, C.: Enhanced mass detection of oligonucleotides using reverse-phase high-performance liquid chromatography/electrospray ionization ion-trap mass spectrometry. Rapid Commun. Mass Spectrom. 16(9), 2133-2141 (2002)

30. Lemaire, D., Marie, G., Serani, L., Laprévote, O.: Stabilization of gasphase noncovalent macromolecular complexes in electrospray mass spectrometry using aqueous triethylammonium bicarbonate buffer. Anal. Chem. 73(8), 1699-1706 (2001)

31. Cavaluzzi, M.J., Borer, P.N.: Revised UV extinction coefficients for nucleoside-5'-monophosphates and unpaired DNA and RNA. Nucleic Acids Res. 32(1), e13 (2004)

32. Ruotolo, B.T., Benesch, J.L., Sandercock, A.M., Hyung, S.J., Robinson, C.V.: Ion mobility-mass spectrometry analysis of large protein complexes. Nat. Protoc. 3(7), 1139-1152 (2008)

33. Gidden, J., Baker, E.S., Ferzoco, A., Bowers, M.T.: Structural motifs of DNA complexes in the gas phase. Int. J. Mass Spectrom. 240(3), 183-193 (2005)

34. Wyttenbach, T., Kemper, P.R., Bowers, M.T.: Design of a new electrospray ion mobility mass spectrometer. Int. J. Mass Spectrom. 212(1), 13-23 (2001)

35. Chaires, J.B.: Human telomeric G-quadruplex: thermodynamic and kinetic studies of telomeric quadruplex stability. FEBS J. 277(5), 10981106 (2010)

36. Karsisiotis, A.I., Hessari, N.M., Novellino, E., Spada, G.P., Randazzo, A., Webba Dasilva, M.: Topological characterization of nucleic acid Gquadruplexes by UV absorption and circular dichroism. Angew. Chem. Int. Ed. Engl. 50(45), 10645-10648 (2011)

37. Dick, D.A.: The distribution of sodium, potassium, and chloride in the nucleus and cytoplasm of Bufo bufo oocytes measured by electron microprobe analysis. J. Physiol. 284, 37-53 (1978)

38. Gabelica, V., Baker, E.S., Teulade-Fichou, M.P., De Pauw, E., Bowers, M.T.: Stabilization and structure of telomeric and c-myc region intramolecular G-quadruplexes: the role of central cations and small planar ligands. J. Am. Chem. Soc. 129(4), 895-904 (2007) 